Supporting Information

Michael L. Tulchinsky and John R. Briggs

One-pot Synthesis of Alkyl 4-Alkoxypentanoates by Esterification and Reductive

Etherification of Levulinic Acid in Alcoholic Solutions 
1. NMR spectra of the new compounds.

${ }^{1} \mathrm{H}$ NMR spectrum of compound $3, \mathrm{CH}_{3} \mathrm{CH}(\mathrm{OBu}) \mathrm{CH}_{2} \mathrm{CH}_{2} \mathrm{COOBu}$, in $\mathrm{CDCl}_{3}$

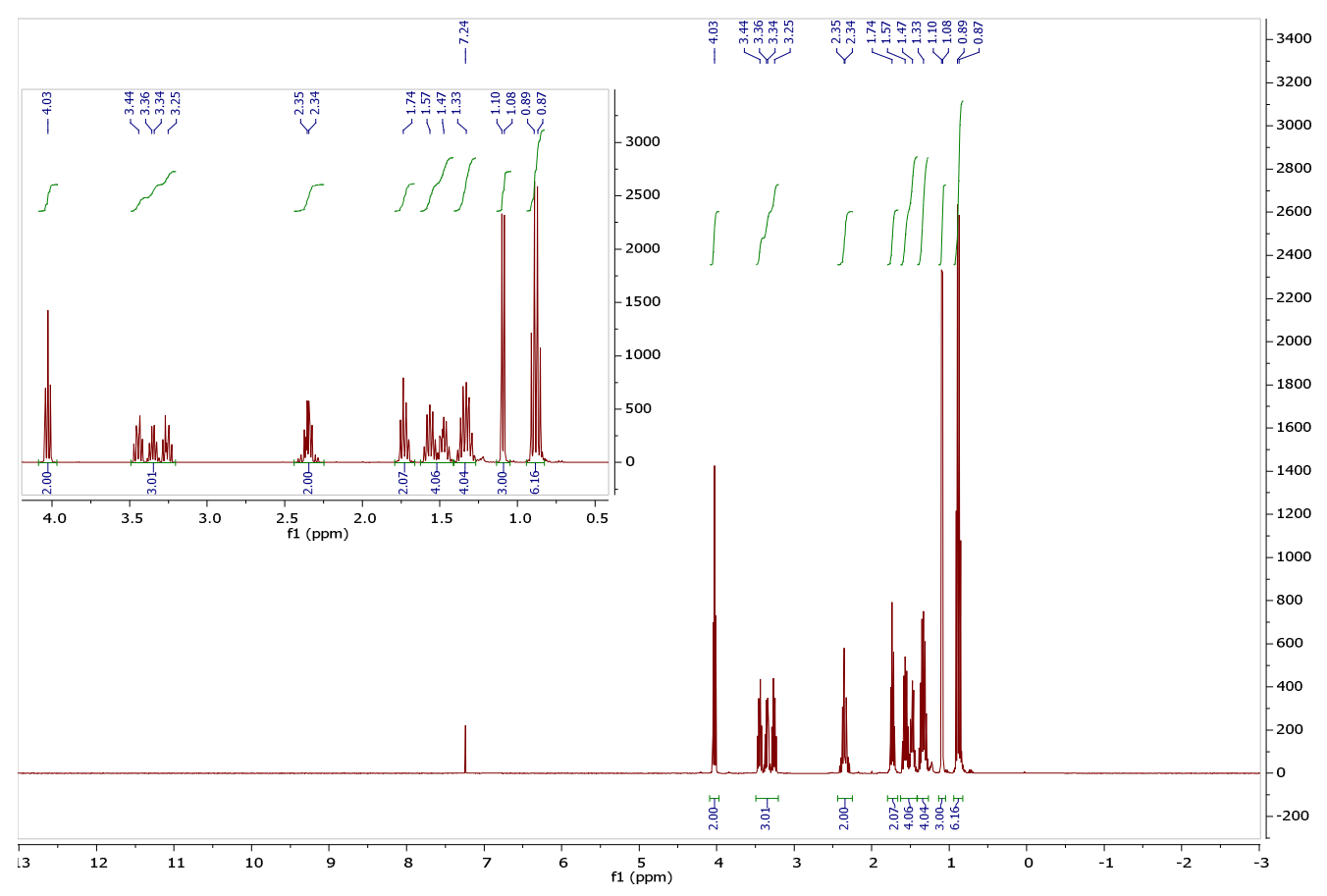

${ }^{13} \mathrm{C}$ NMR spectrum of compound $3, \mathrm{CH}_{3} \mathrm{CH}(\mathrm{OBu}) \mathrm{CH}_{2} \mathrm{CH}_{2} \mathrm{COOBu}$, in $\mathrm{CDCl}_{3}$

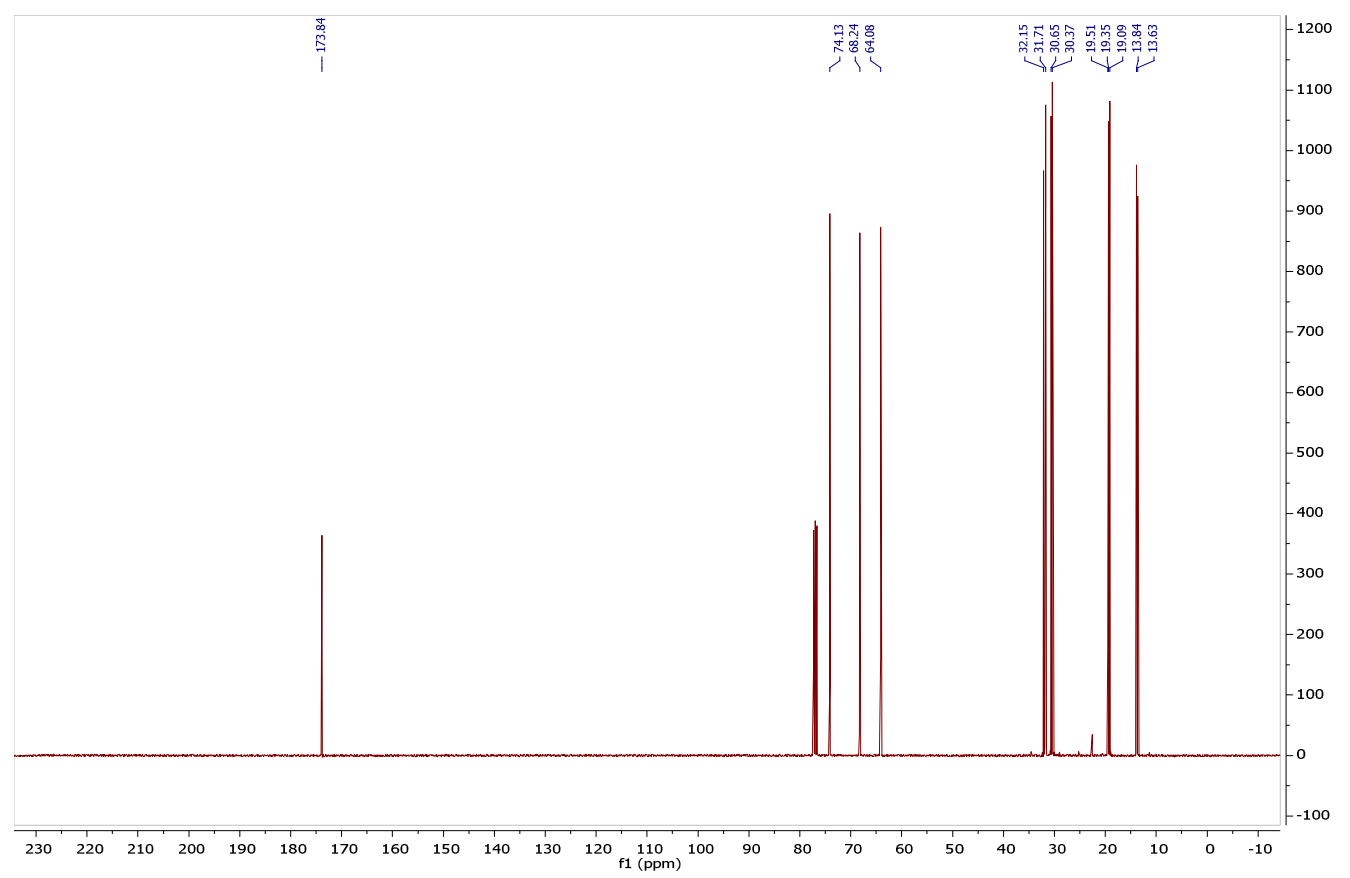


${ }^{1} \mathrm{H}$ NMR spectrum of compound 4, $\mathrm{CH}_{3} \mathrm{CH}\left(\mathrm{OC}_{7} \mathrm{H}_{15}\right) \mathrm{CH}_{2} \mathrm{CH}_{2} \mathrm{COOC}_{7} \mathrm{H}_{15}$, in $\mathrm{CDCl}_{3}$

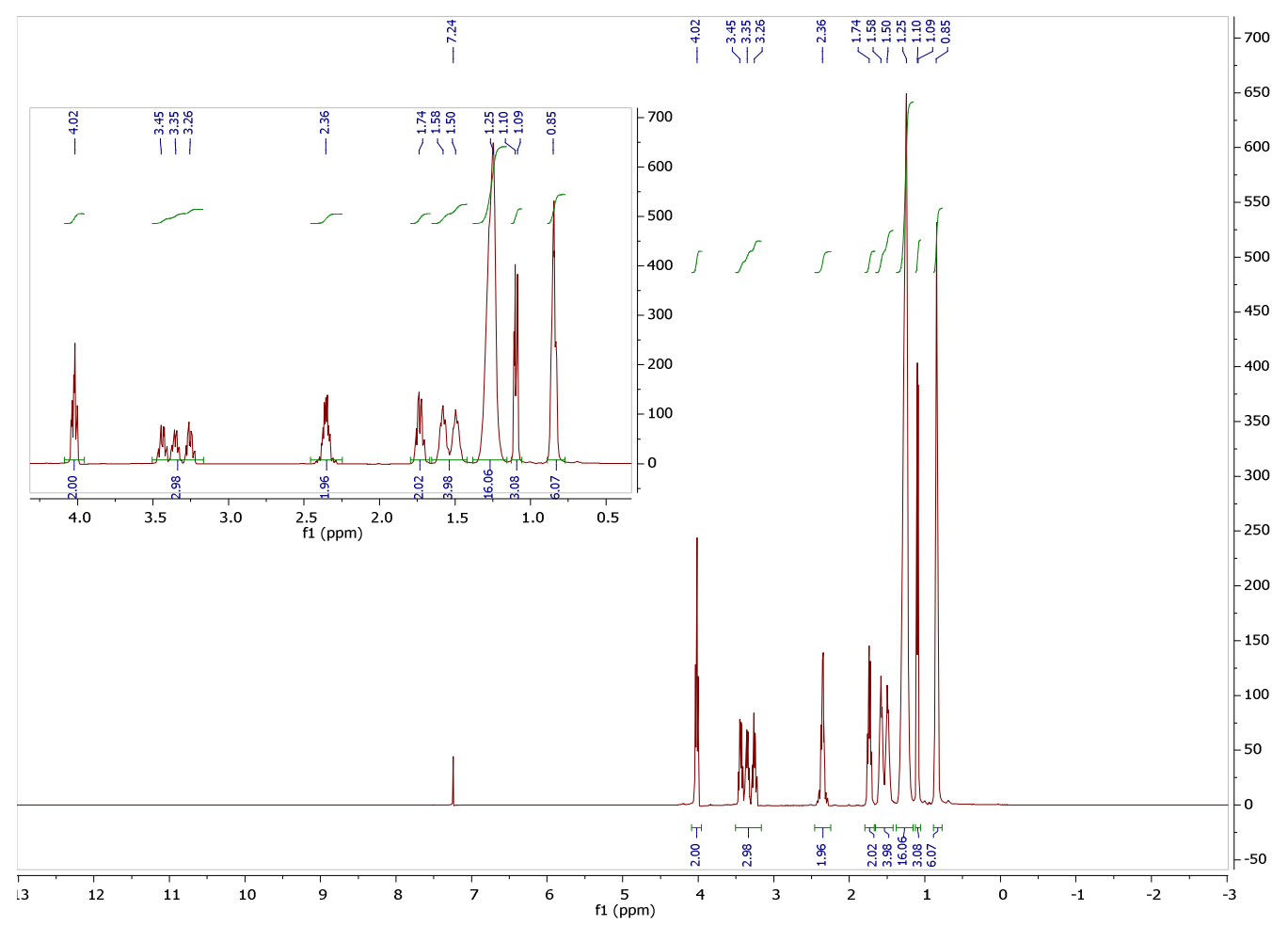

${ }^{13} \mathrm{C}$ NMR spectrum of compound $4, \mathrm{CH}_{3} \mathrm{CH}\left(\mathrm{OC}_{7} \mathrm{H}_{15}\right) \mathrm{CH}_{2} \mathrm{CH}_{2} \mathrm{COOC}_{7} \mathrm{H}_{15}$, in $\mathrm{CDCl}_{3}$

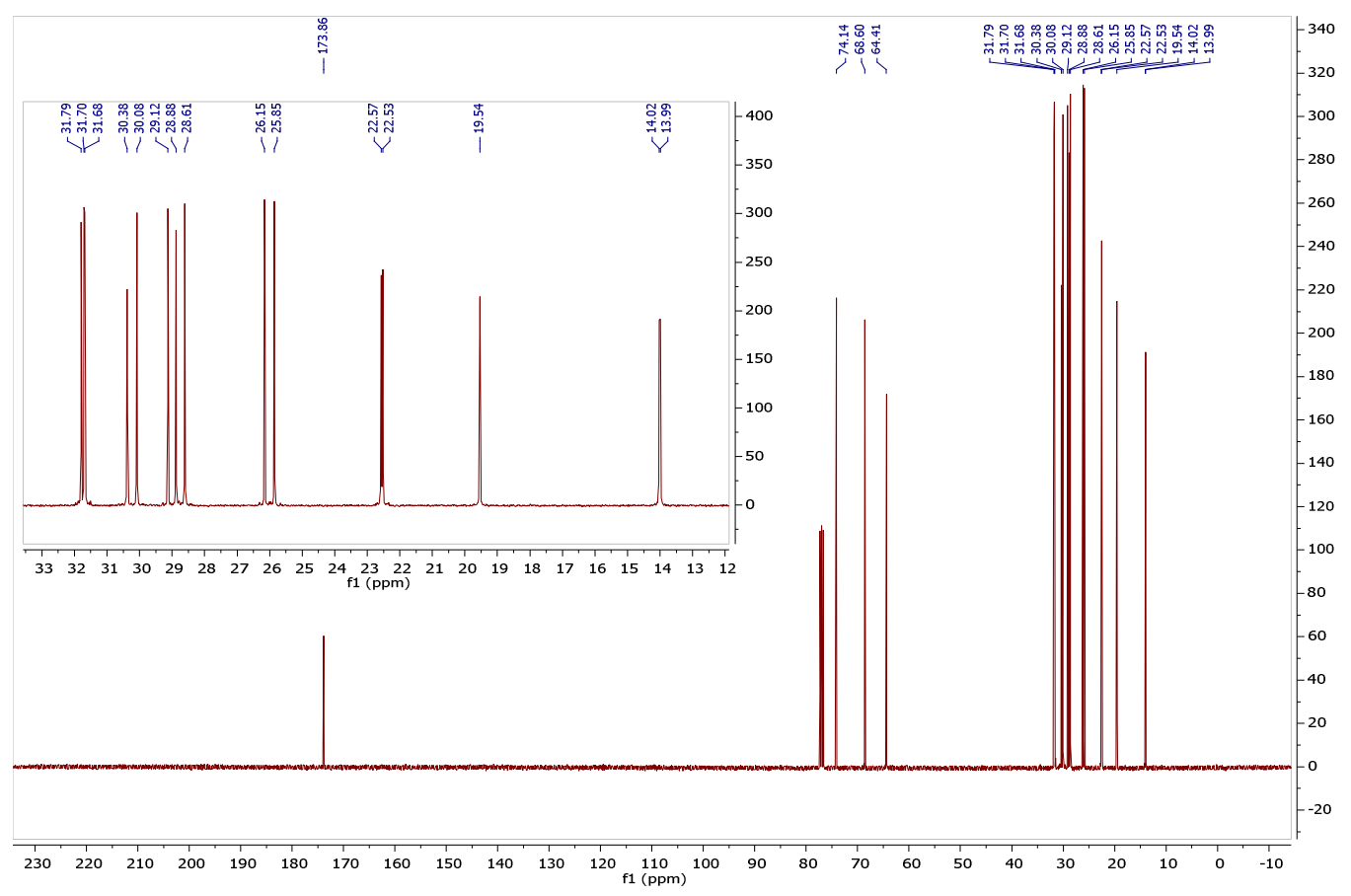




\section{GC/MS SPECTRA}

Compound 3, butyl 4-butoxypentanoate
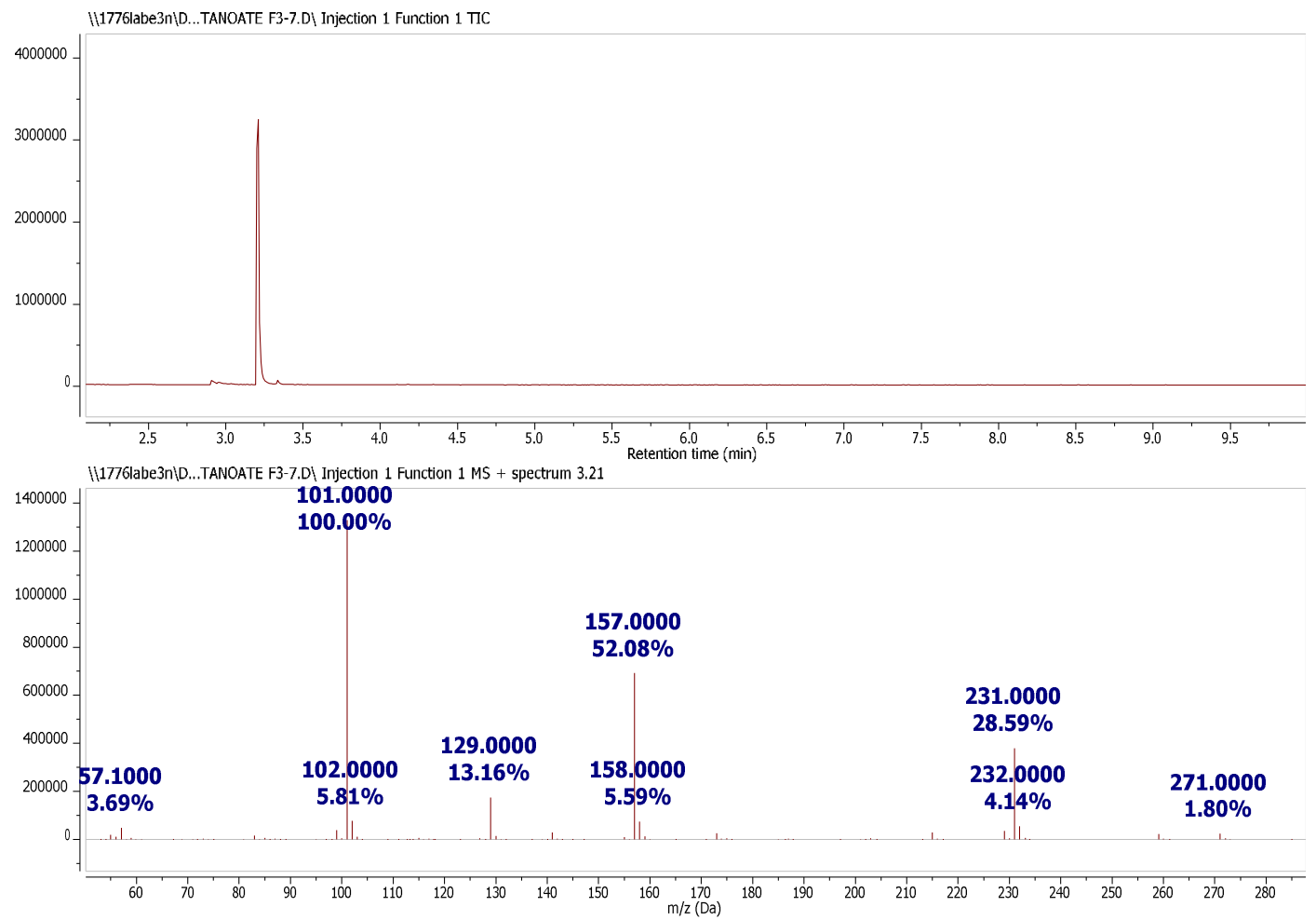

Compound 4, heptyl 4-heptyloxypentanoate 

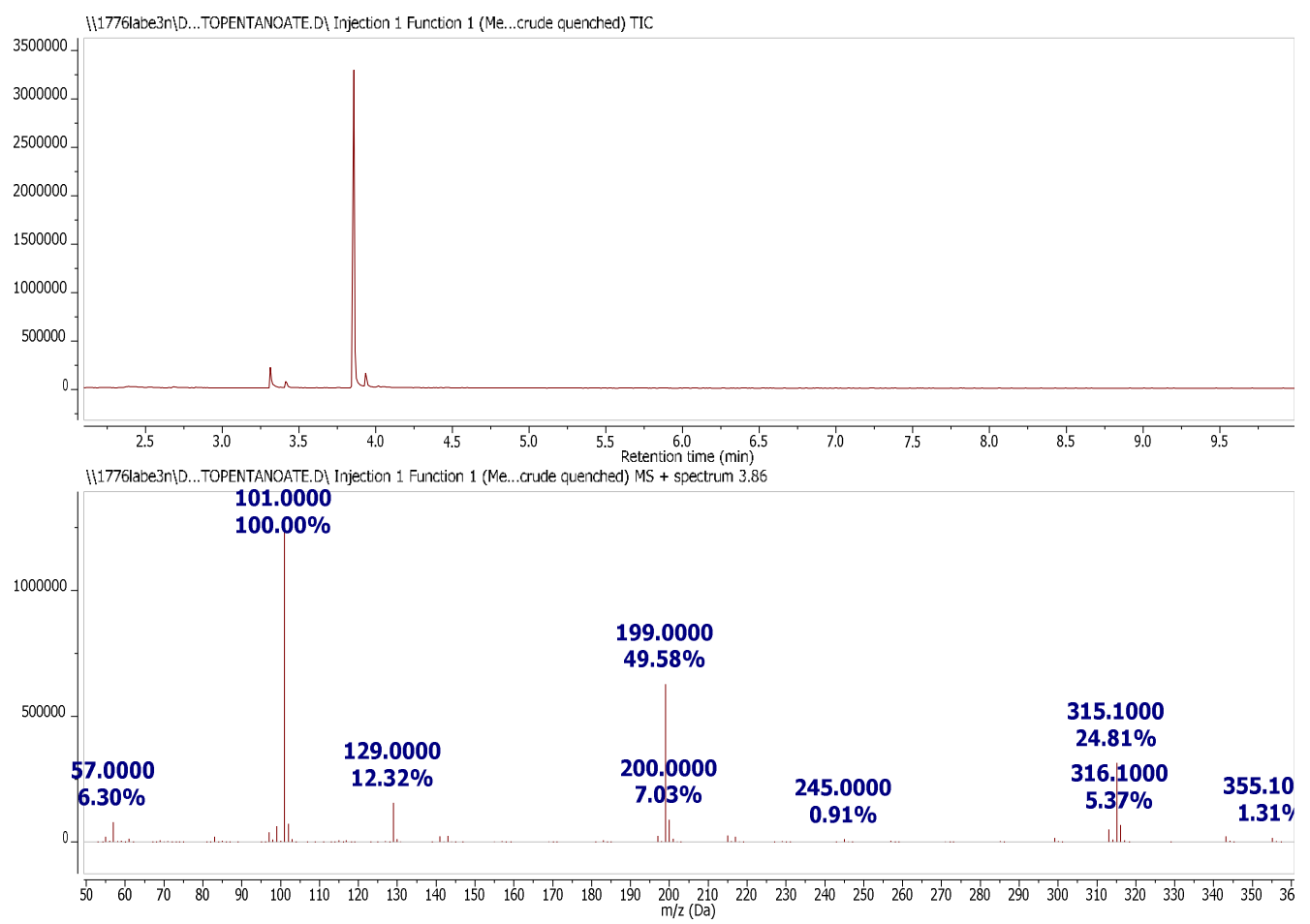

\section{HIGH RESOLUTION MS SPECTRA}

Compound $\mathbf{3}$ in protonated form, protonated butyl 4-butoxypentanoate

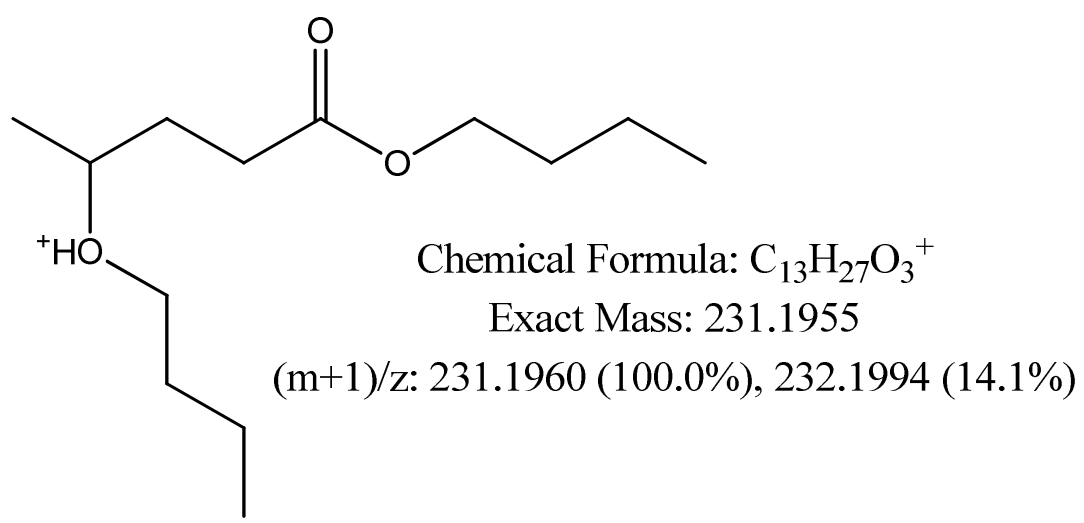




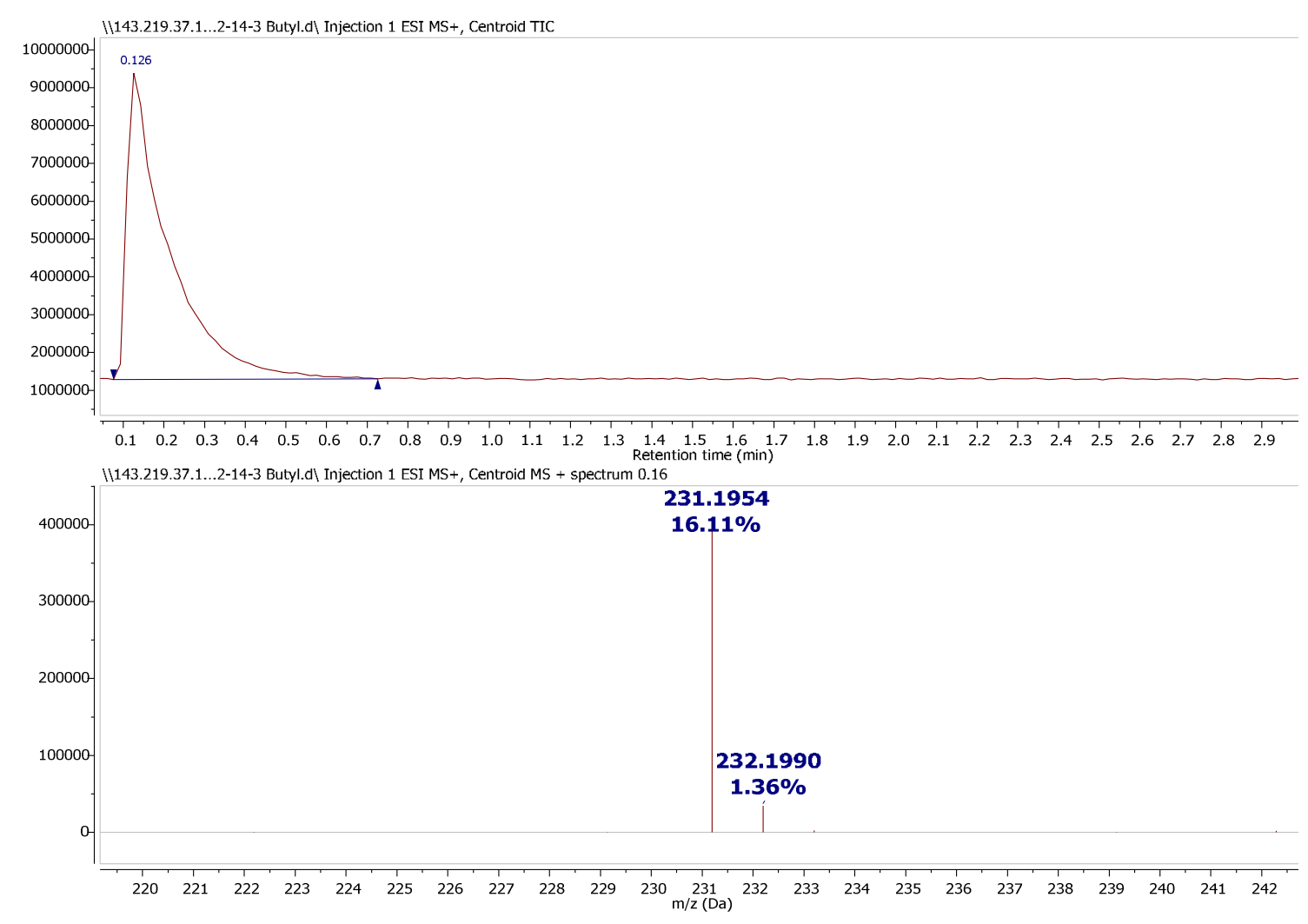

Compound $\mathbf{4}$ in protonated form, protonated heptyl 4-heptyloxypentanoate

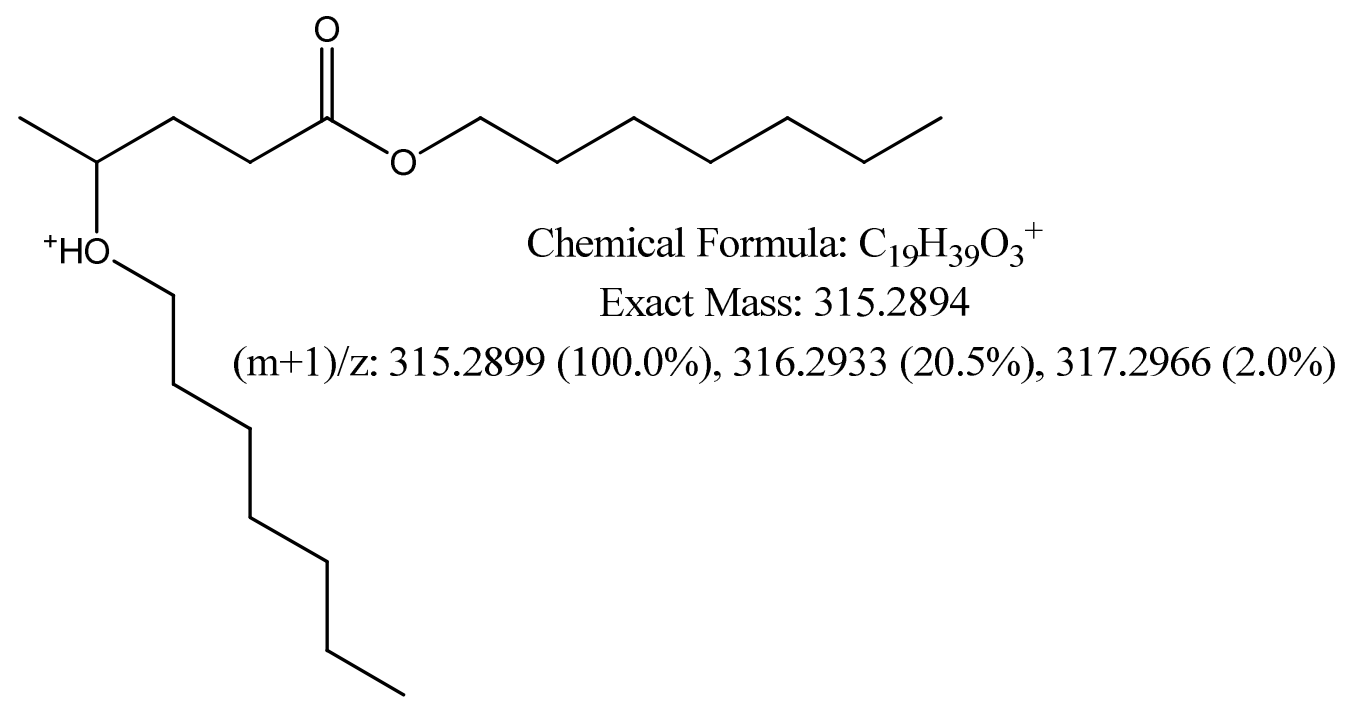




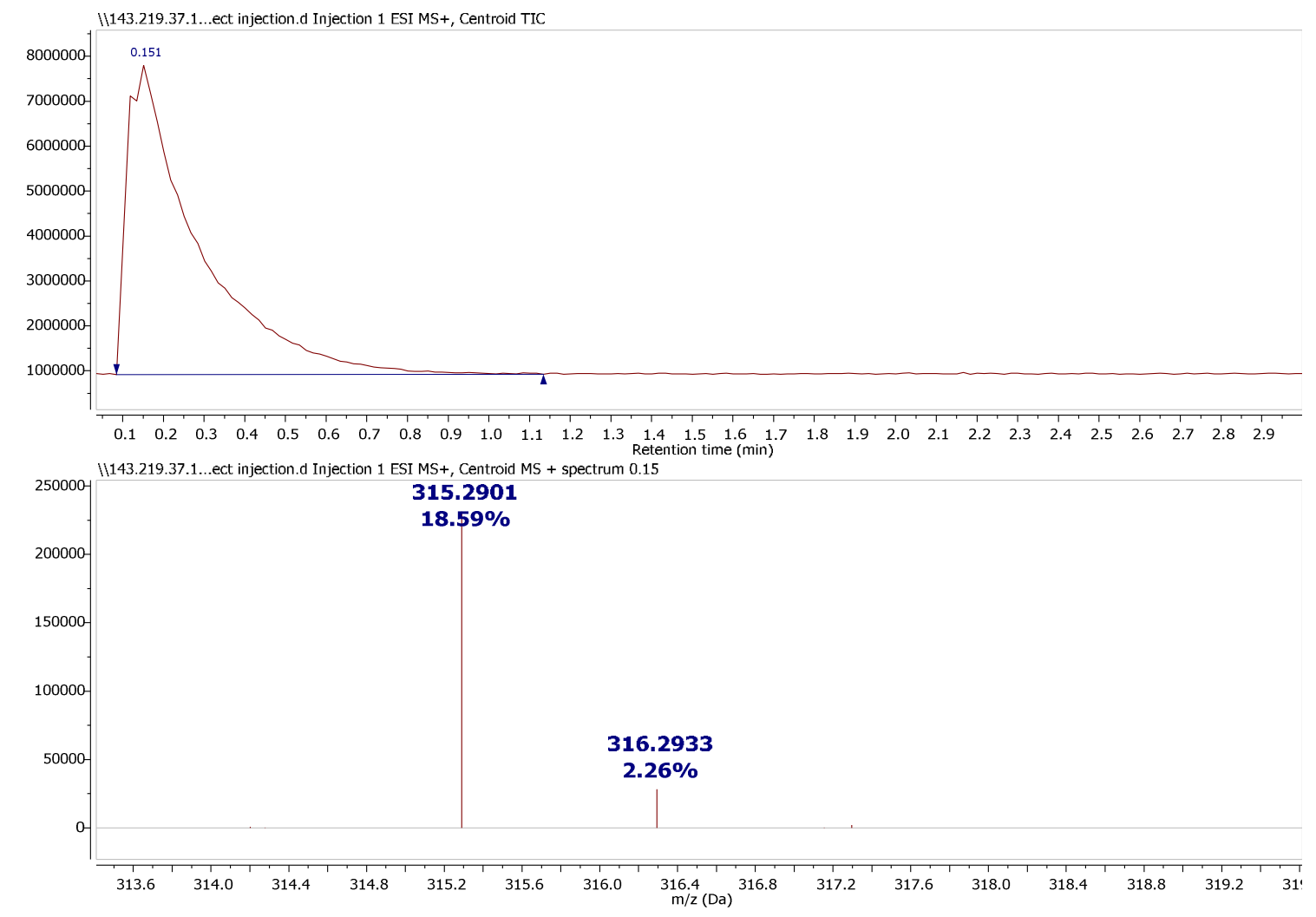




\section{ACCURATE MASS GC-CI-MS ANALYSIS OF THE REDUCTIVE ETHERIFICATION OF LEVULINIC ACID WITH 1-HEPTANOL MIXTURE}

Total ion chromatograms from the accurate mass GC-MS analysis of the reductive etherification extract:

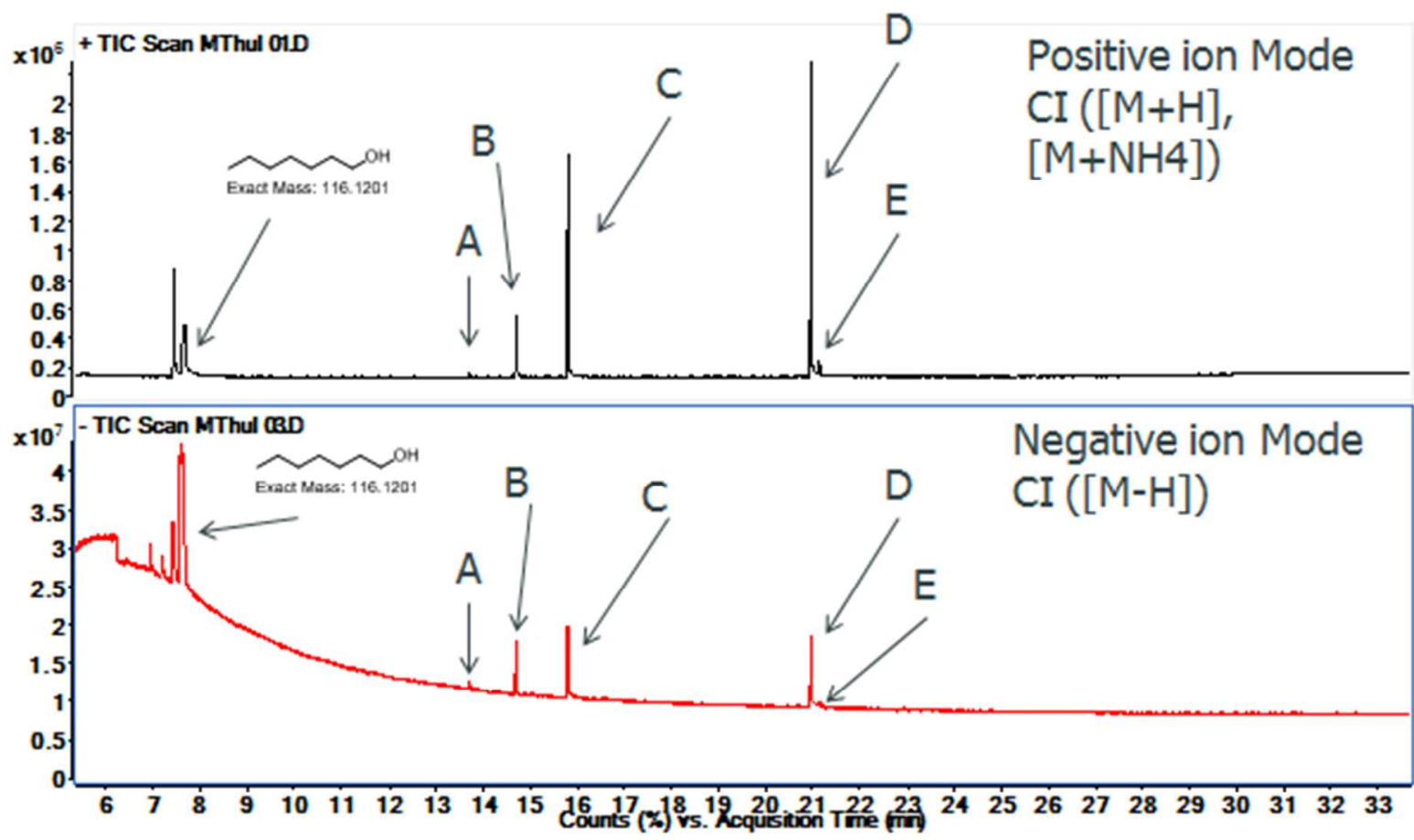

Mass spectra from the accurate mass GC-MS analysis of compound A:

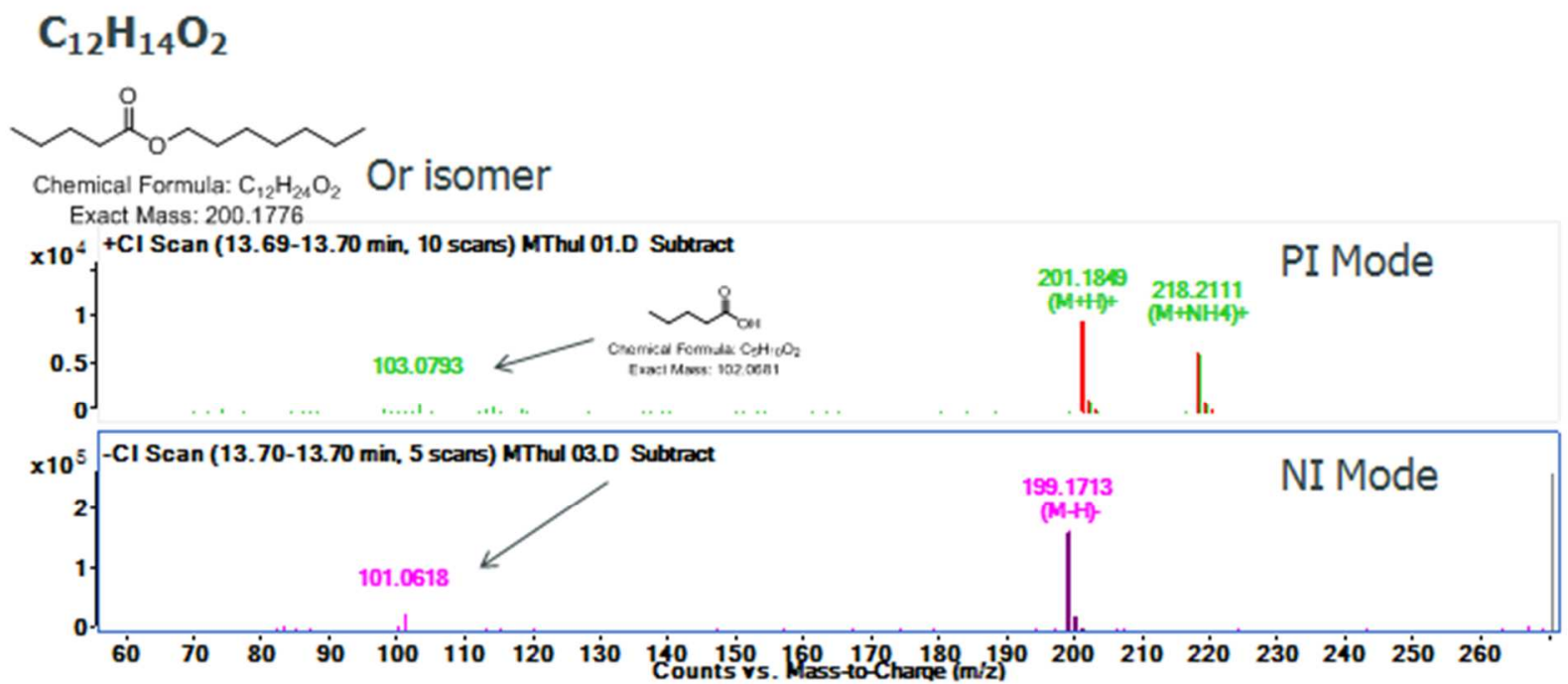

Mass spectra from the accurate mass GC-MS analysis of compound B: 


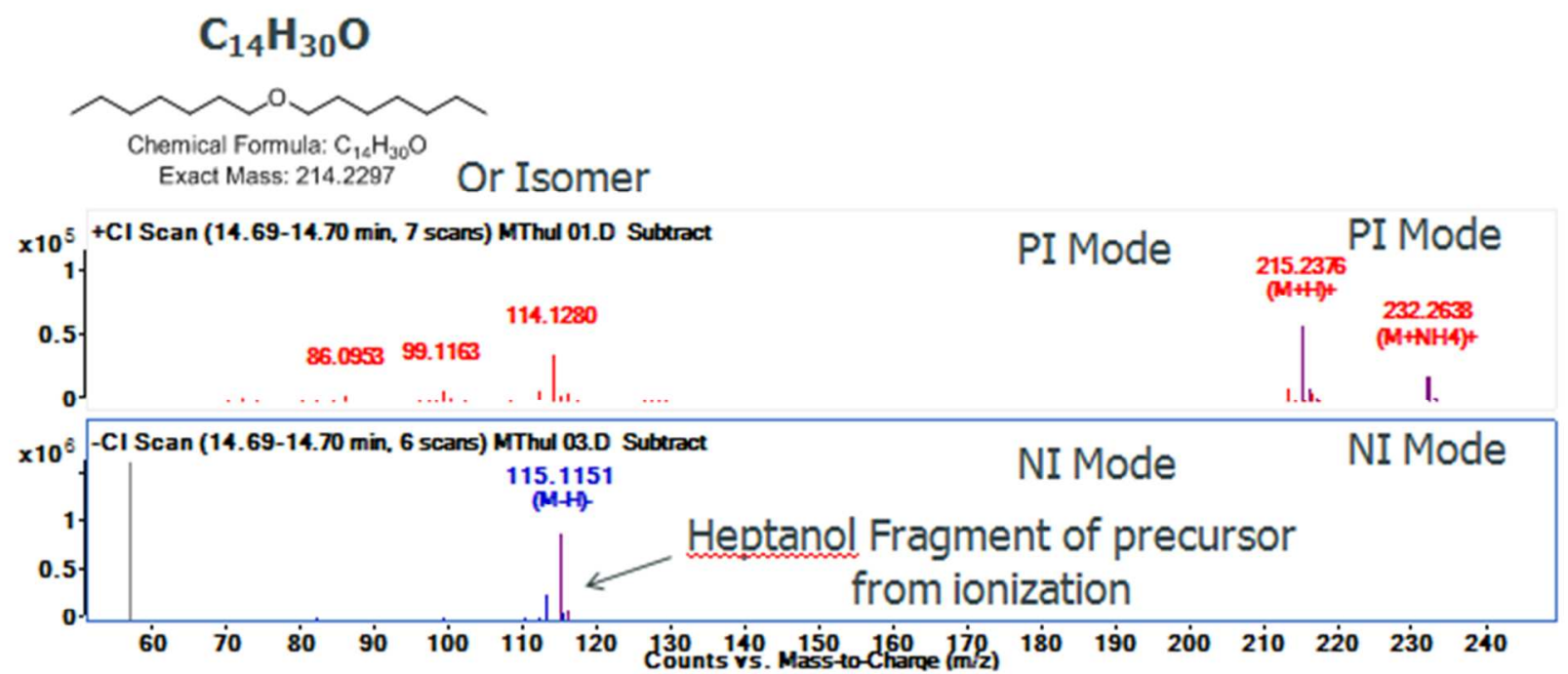

Mass spectra from the accurate mass GC-MS analysis of compound C:

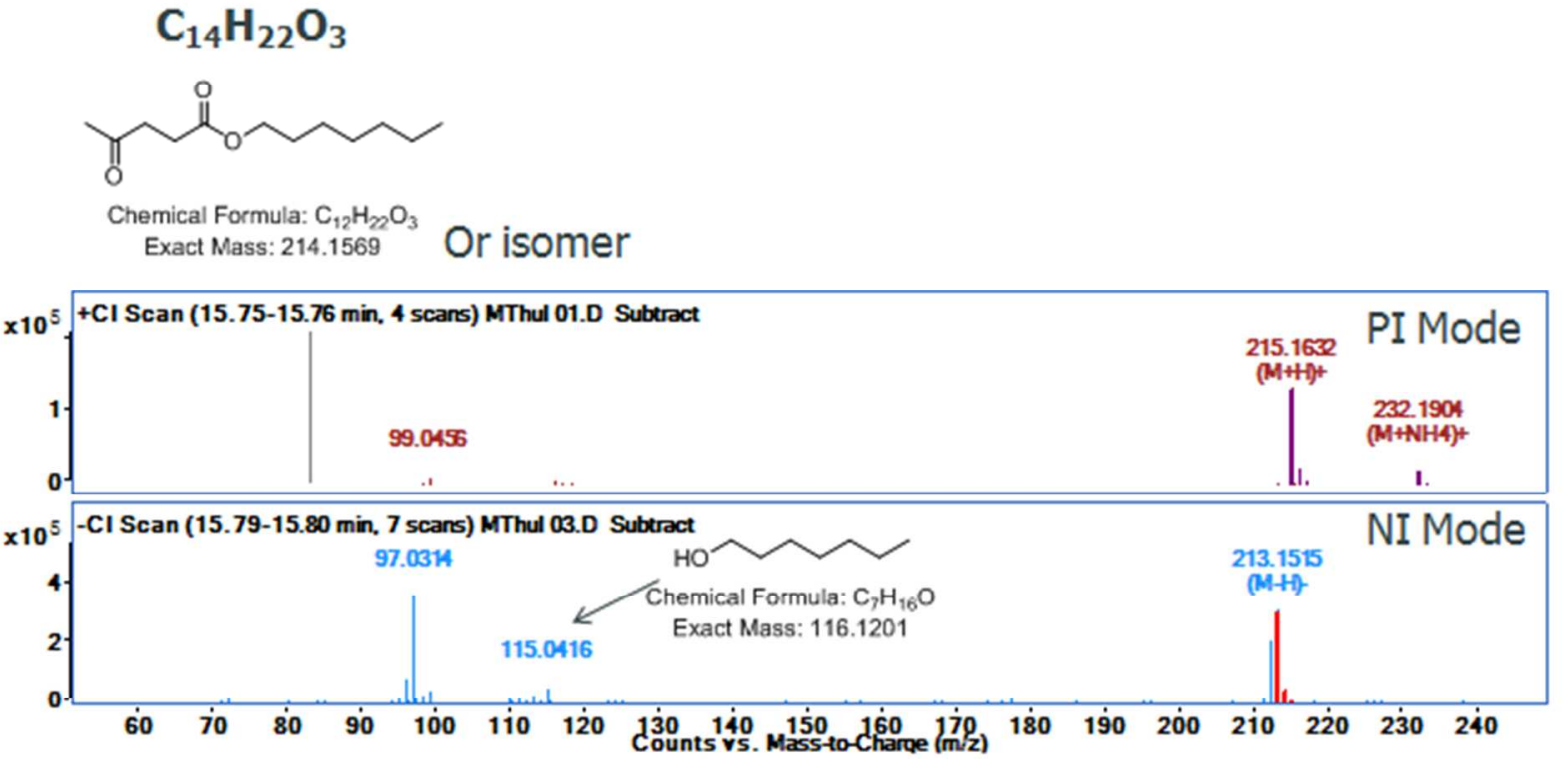

Mass spectra from the accurate mass GC-MS analysis of compound D: 

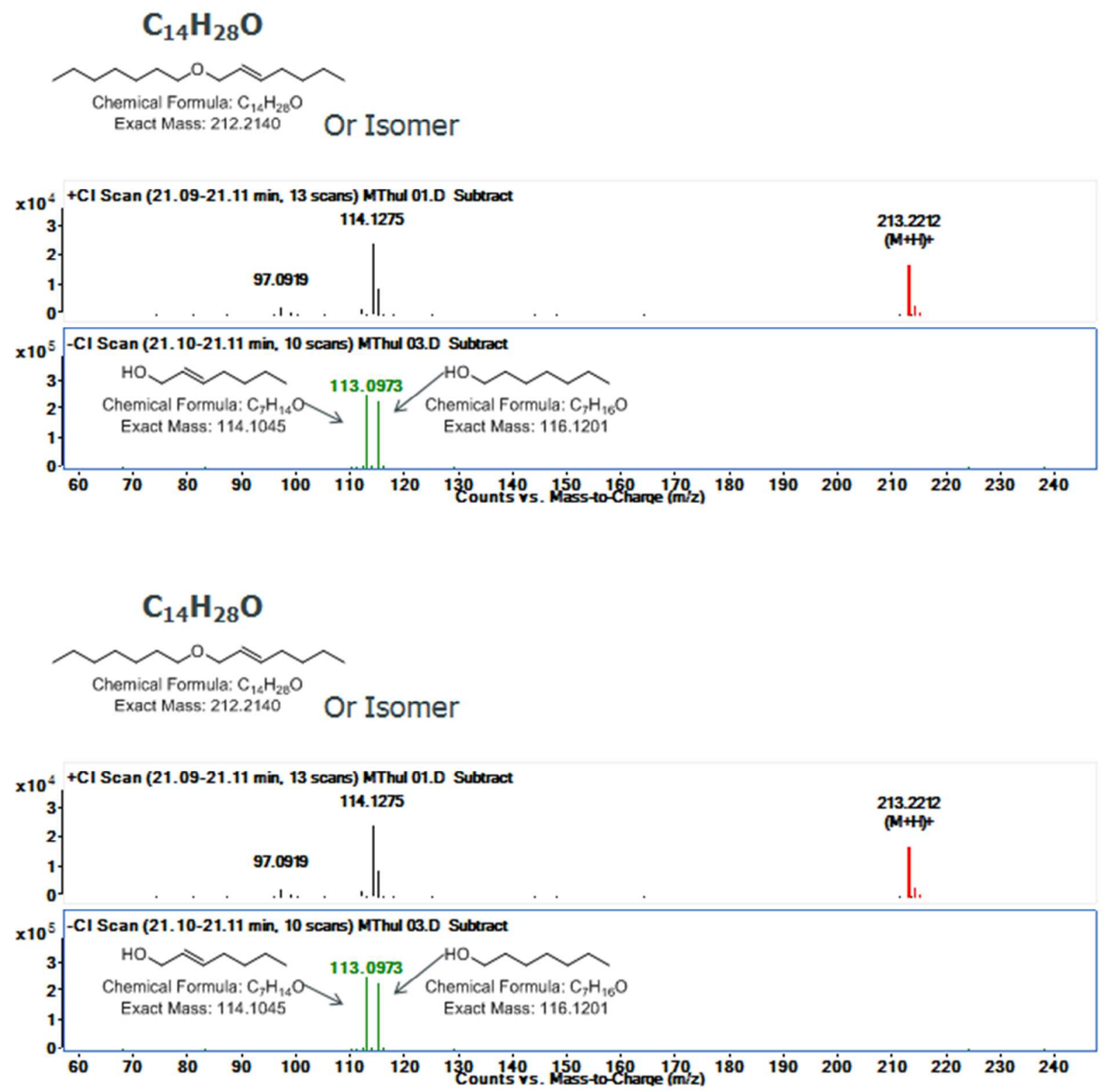

\section{ACCURATE MASS GC-CI-MS ANALYSIS OF THE REDUCTIVE ETHERIFICATION OF LEVULINIC ACID WITH 1-HEPTANOL MIXTURE}

A reaction of levulinic acid and 1-heptanol was carried out at $200^{\circ} \mathrm{C}$ for 2 hours in the presence of $5 \% \mathrm{Pd} / \mathrm{C}$ but without hydrogen.

A small signal at 22.3 min was identified as the enol ether which is an intermediate in the proposed mechanism: 


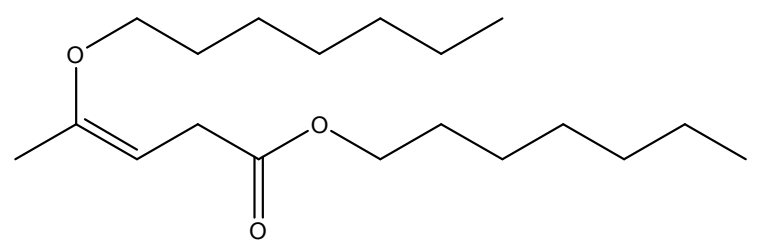

Chemical Formula: $\mathrm{C}_{19} \mathrm{H}_{36} \mathrm{O}_{3}$ Exact Mass: 312.2664

Total ion chromatogram from the accurate mass GC-MS analysis of the levulinic $\mathrm{acid} / \mathrm{heptanol}$ mixture with $5 \% \mathrm{Pd} / \mathrm{C}$ kept at $200{ }^{\circ} \mathrm{C}$ for $2 \mathrm{~h}$ without hydrogen:

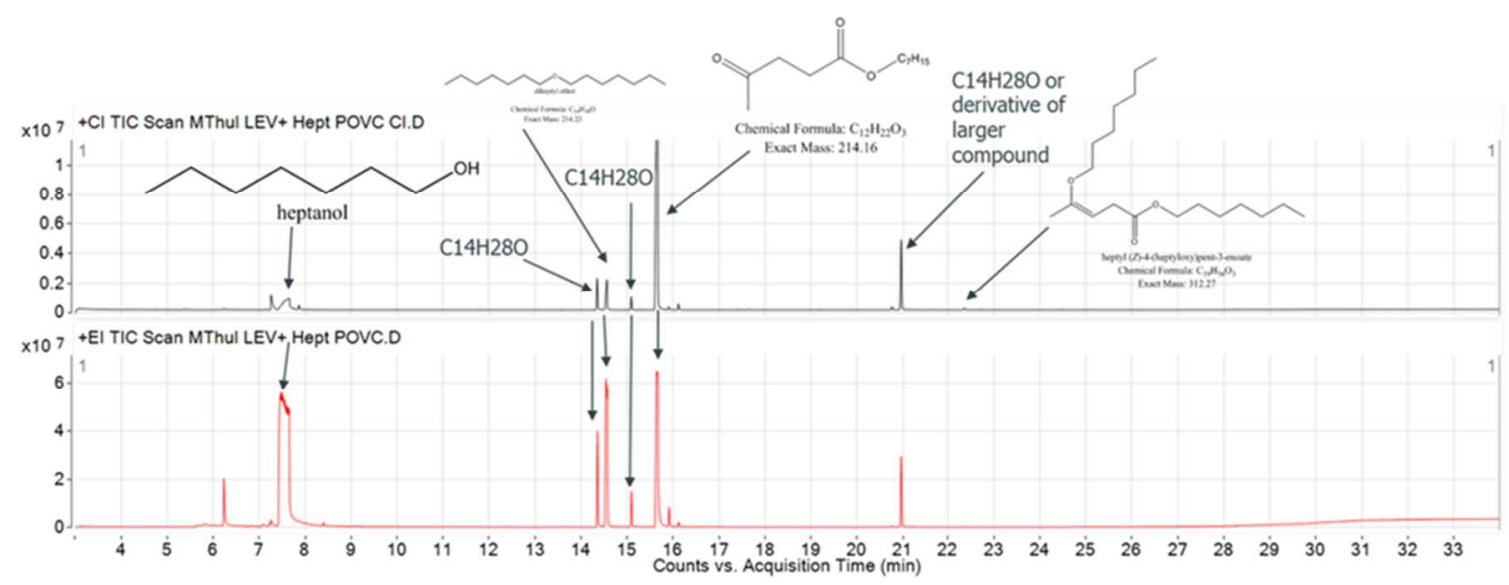

Mass spectrum from timepoint 22.3 min (target intermediate) supports the structure:

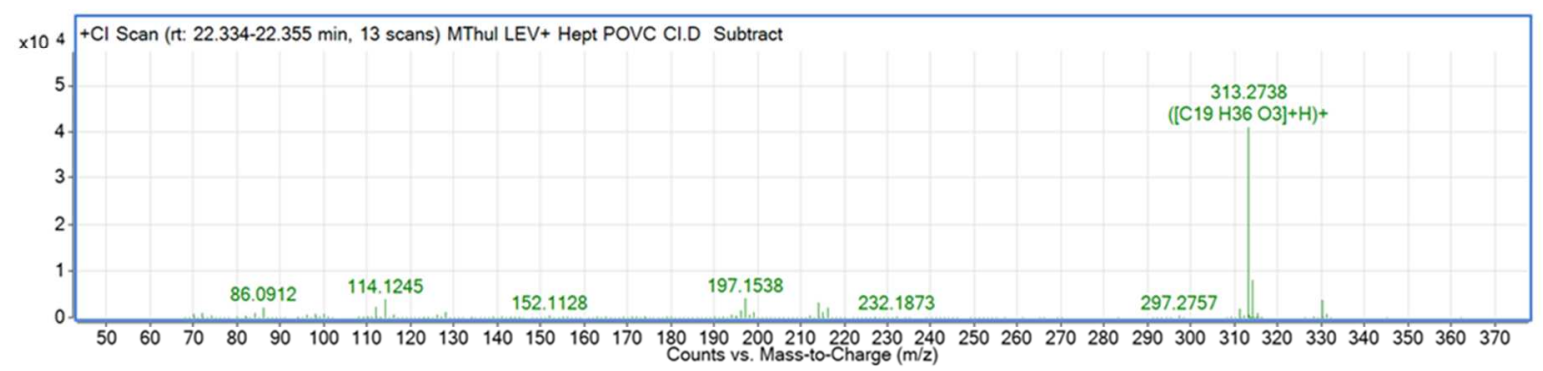

